\title{
Topical Treatment of Psoriasis Vulgaris: The Swiss Treatment Pathway
}

\author{
Julia-Tatjana Maula Florian Anzengruber $^{\mathrm{a}}$ Curdin Conrad $^{\mathrm{b}}$ Antonio Cozzio $^{\mathrm{c}}$ \\ Peter Häusermann $^{d}$ Ahmad Jalilie Antonios G.A. Kolios ${ }^{f, g}$ Emmanuel Laffitte $^{h}$ \\ Anne-Karine Lapointe ${ }^{i}$ Carlo Mainetti ${ }^{j}$ Christoph Schlapbach ${ }^{k}$ Ralph Trüebl \\ ${\text { Nikhil Yawalkark }{ }^{k} \text { Michaela Dippel }}^{m} \quad$ Alexander A. Navarini $^{d}$ \\ ${ }^{a}$ Department of Dermatology and Venereology, University Hospital of Zurich (USZ), Zurich, Switzerland; \\ ${ }^{b}$ Department of Dermatology and Venereology, University Hospital of Vaude (CHUV), Lausanne, Switzerland; \\ 'Department of Dermatology and Venereology and Allergology, Kantonsspital St. Gallen, St. Gallen, Switzerland; \\ ${ }^{\mathrm{d}}$ Department of Dermatology and Venereology, University Hospital of Basel, Basel, Switzerland; ${ }^{e}$ Dermatology and \\ Skin Care, Bürgenstock Medical Center, Obbürgen, Switzerland; ${ }^{f}$ Department of Immunology, University Hospital \\ of Zurich, Zurich, Switzerland; ${ }^{9}$ Department of Medicine, Beth Israel Deaconess Medical Center, Harvard Medical \\ School, Boston, MA, USA; h Department of Dermatology and Venereology, University Hospital of Geneva (HUG), \\ Geneva, Switzerland; 'Private Practice for Dermatology and Venereology, Lausanne, Switzerland; 'Department \\ of Dermatology and Venereology, Regional Hospital of Bellinzona, Bellinzona, Switzerland; 'Department \\ of Dermatology and Venereology, Inselspital, University Hospital of Berne, Berne, Switzerland; 'Center for \\ Dermatology and Hair Diseases, Zurich, Switzerland; ${ }^{\mathrm{m}}$ MD Medscript and Consult, Wachenheim, Germany
}

\section{Keywords}

Psoriasis · Topical management · Fixed combination •

Corticosteroids · Calcineurin inhibitors · Vitamin $D_{3}$ analogues

\begin{abstract}
Topical treatment is crucial for the successful management of plaque psoriasis. Topicals are used either as a stand-alone therapy for mild psoriasis or else in combination with UV or systemic treatment for moderate-to-severe disease. For the choice of a suitable topical treatment, the formulation matters and not just the active substances. This expert opinion paper was developed via a non-structured consensus process by Swiss dermatologists in hospitals and private practices to illustrate the current treatment options to general practitioners and dermatologists in Switzerland. Defining treatment goals together with the patient is crucial and in-
\end{abstract}

(C) 2021 The Author(s)

Published by S. Karger AG, Basel

This article is licensed under the Creative Commons Attribution 4.0 International License (CC BY) (http://www.karger.com/Services/ OpenAccessLicense). Usage, derivative works and distribution are permitted provided that proper credit is given to the author and the original publisher. creases treatment adherence. Patients' personal preferences and pre-existing experiences should be considered and their satisfaction with treatment and outcome regularly assessed. During the induction phase of "classical" mild-to-moderate psoriasis, the fixed combination of topical calcipotriol (Cal) $50 \mu \mathrm{g} / \mathrm{g}$ and betamethasone dipropionate (BD) $0.5 \mathrm{mg} / \mathrm{g}$ once daily is frequently used for $4-8$ weeks. During the maintenance phase, a twice weekly (proactive) management has proved to reduce the risk of relapse. Of the fixed combinations, Cal/BD aerosol foam is the most effective formulation. However, the individual choice of formulation should be based on a patient's preference and the location of the psoriatic plaques. Tailored recommendations are given for the topical management of specific areas (scalp, facial, intertriginous/genital, or palmoplantar lesions), certain symptoms (hyperkeratotic or hyperinflammatory forms) as well as during pregnancy or a period of breastfeeding. As concomitant basic therapy, several emollients are recommended. If topi- 
cal treatment alone does not appear to be sufficient, the regimen should be escalated according to the Swiss S1-guideline for the systemic treatment of psoriasis.

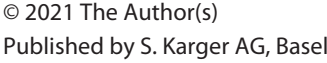

\section{Introduction}

Psoriasis vulgaris is a chronic inflammatory skin disease that can be triggered and/or maintained by endogenous and/or exogenous factors [1]. About $70-80 \%$ of psoriasis patients suffer from mild-to-moderate disease that can be successfully controlled with topical treatments [2]. In moderate-to-severe cases, which are usually treated with UV or systemic anti-inflammatory or biological therapies, concomitant topical treatments can support the efficacy of systemic treatments [3].

Mild psoriasis is defined either as an affected body surface area (BSA) of $\leq 10 \%$, or a Psoriasis Area and Severity Index (PASI) $\leq 10$ and a Dermatological Life Quality In$\operatorname{dex}(\mathrm{DLQI}) \leq 10$, respectively. Exceptions are defined as so-called "upgrade criteria"; if visible (e.g., on the face, scalp, hands, or nails) and/or therapy-refractory regions are affected, psoriasis can be assessed as moderate-to-severe, even if the affected BSA is $<10 \%$ or the PASI is $<10$ [4]. This is reflected by a DLQI of $>10$.

Due to a median disease duration of about 50 years, psoriasis and its management can severely affect patient's quality of life (QoL). It has been found that psoriasis causes an even greater reduction in QoL than tumours or coronary heart disease [5]. Furthermore, patients with psoriasis, especially when onset is at a young age, have significantly fewer employment opportunities [6]. Effective short- and long-term management of psoriasis is therefore crucial to ensure sufficient control of the disease, limit the burden of disease and the impact on QoL and the ability to work.

Despite the fact that most cases of psoriasis can be successfully managed with topical treatments, regular updates of guidelines on topical psoriasis treatment, with respect to the latest evidence and the latest developments of the formulations, are lacking. While specific guidelines on systemic treatment are available for Switzerland [7] and are updated regularly, there are no Swiss guidelines for the topical treatment of psoriasis. Furthermore, various individual disease characteristics, e.g., hyperkeratotic or hyperinflammatory forms, and certain locations, i.e., the scalp, face, intertriginous areas, palms and soles of the feet, require specific considerations for topical treatment, as do certain life circumstances such as pregnancy and breastfeeding.

Swiss Treatment Pathway for Topical

Treatment of Psoriasis
This pathway aims to optimise the use and the outcome of topical treatment for the short- and long-term management of psoriasis in adults, as well as in specific treatment situations. It was developed by an informal expert consensus panel of dermatologists from Switzerland and is based on the recently published German treatment pathway [8]. It aims to provide general practitioners and dermatologists in Switzerland with practical strategies for the topical management of mild-to-moderate psoriasis as well as including useful Swiss-specific regulatory aspects.

\section{The Goal of Treatment: Satisfaction with Treatment and Outcome}

Defining treatment goals determines adherence, manages expectations, and avoids treatment failures. Goals are important to provide patients with short- and longterm perspectives for their disease. The ultimate goal of psoriasis treatment is the complete clearance of all skin symptoms; however, realistically, it is not possible to achieve this in all patients and/or cannot be permanently maintained because psoriasis is a chronic and recurring disease. Whereas a PASI 75/90/100 improvement and the more recently established [9] absolute PASI $\leq 2$ or Physician Global Assessment (PGA) 0/1 are commonly used outcome parameters in clinical trials, those severity parameters are not regularly assessed by all physicians in daily practice for cases of mild-to-moderate psoriasis.

We are in consensus that patient satisfaction should be considered the primary criterion when assessing the goals and success of treatment.

In daily practice, the assessment of patient satisfaction can be done by asking a question that requires a simple answer "Yes" or "No" as to whether a patient is satisfied with the treatment or treatment outcome. If a patient is not satisfied, and before deciding on the next step, i.e., to continue or change the treatment, it is recommended that the cause of discontent be explored further by examining the following aspects:

- Efficacy, e.g., the extent of the improvement of symptoms, expectation about efficacy/onset of action

- Tolerability, e.g., burning sensations and other side effects

- Formulation, e.g., expectations about the texture

- Comfort, e.g., expectations about the frequency, time taken, ease of application, the scent, etc.

- Compliance, e.g., how patients apply the formulation: too sparingly or inconsistently, if they sometimes forget to apply, etc. 
Fig. 1. Topical treatment pathway for plaque psoriasis (images used with the courtesy of J.-T.M.). * Consider the "upgrade criteria" [4]. ** TCS should not be prescribed for daily use for $>8$ weeks and ideally for only 2-4 weeks and then with reduced frequency (class IV for a maximum of 2-4 weeks). BD, betamethasone dipropionate; BSA, body surface area; $\mathrm{Cal}$, calcipotriol; DLQI, Dermatological Life Quality Index; PASI, Psoriasis Area and Severity Index; TCS, topical corticosteroids; Tx, treatment; w, week; d, day.

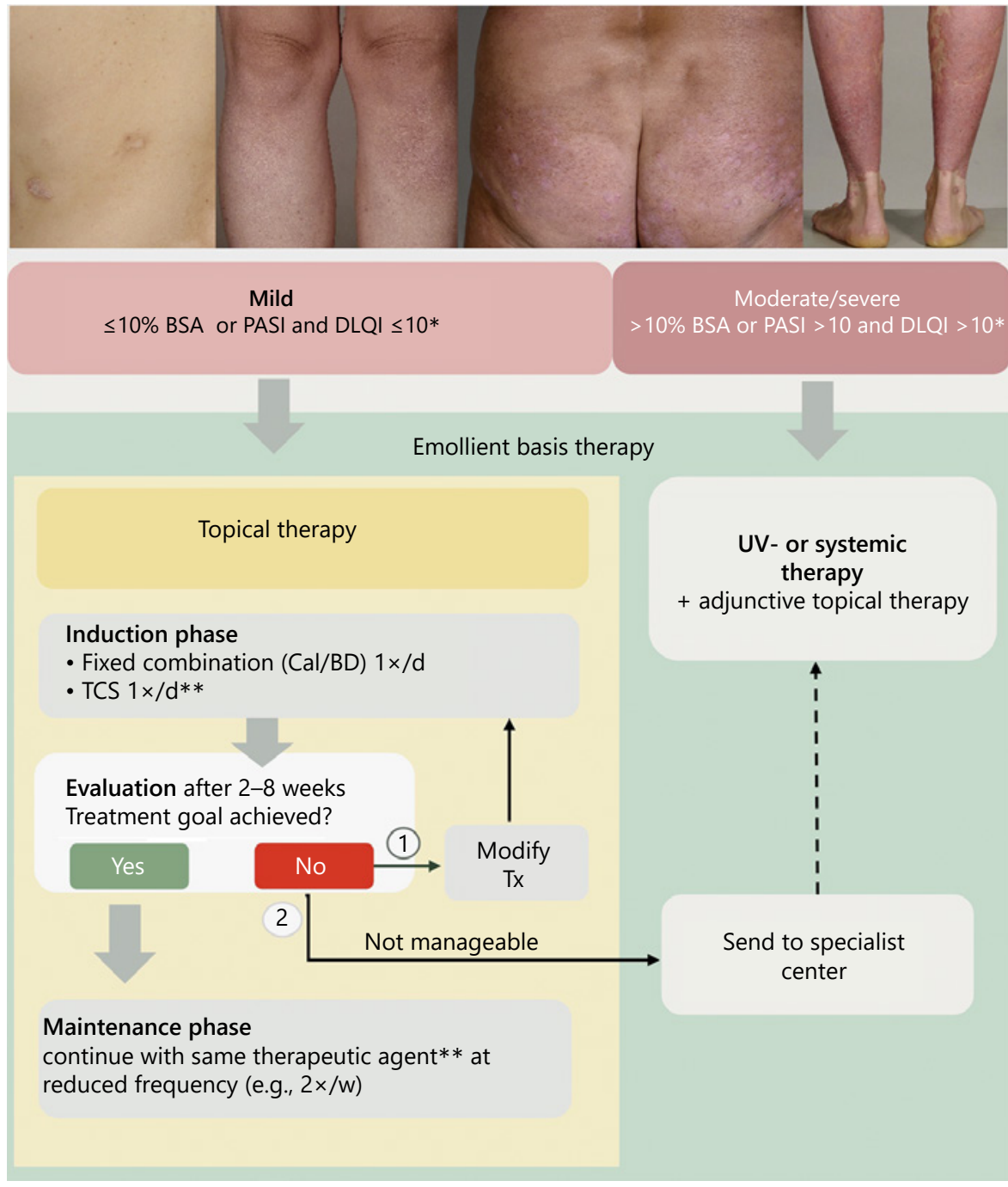

It is important to realise that, especially in topical therapy of psoriasis, patients must be motivated regularly and re-encouraged on the correct way of application and frequency to ensure adherence over time and to achieve an optimal result. Patients' expectations need to be understood and managed individually in parallel $[10,11]$.

\section{Treatment Pathway}

\section{General Recommendations}

Joint Decision Process. In general, topical management of psoriasis should be based on a joint decision with the patient regarding the various treatment options, the time to response, and the expected outcome. A patient's per- sonal preference and previous treatment experience should be considered, and a simple, once-daily treatment regimen is preferable. Clear and written instructions on the manner and frequency of application as well as the amount to be applied can help to ensure treatment adherence $[12,13]$.

Concomitant Emollients/Basis Therapy. Daily basis therapy with emollients should restore the barrier function of the skin, prevent or interrupt flare-ups, improve skin elasticity, and maintain the balance of the skin's microbiome [14]. Emollients containing urea 5-10\%, salicylic acid, ceramides, niacinamide, or thermal water have been shown to be beneficial to psoriasis lesional and nonlesional skin [15].

Follow-Up. In general, patients should be followed up every 12 weeks during the induction and maintenance 
Table 1. Recommendations for the topical treatment of "classical" mild-to-moderate psoriasis, and at specific locations or with specific symptoms

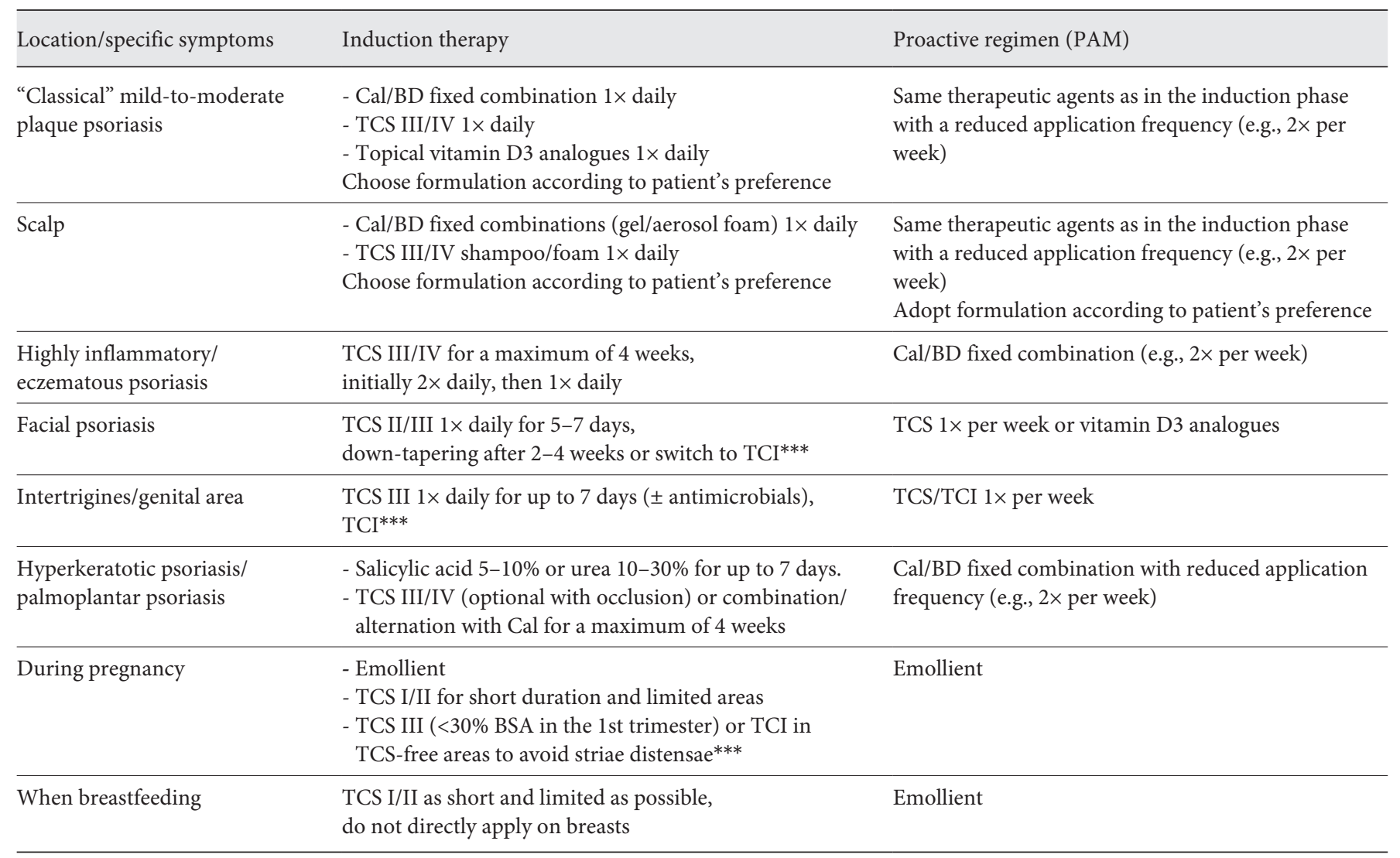

*** Off-label for psoriasis. BD, betamethasone dipropionate; BSA, body surface area; Cal, calcipotriol; PAM, proactive management; TCS, topical corticosteroid; TCI, topical calcineurin inhibitor.

phases. If the treatment goal is not achieved after 4-8 weeks, patients should ask for another appointment.

Escalation of Treatment Options. If the patient is not satisfied and the reasons for this have been thoroughly explored, the physician should choose one of the following options:

- continue the therapy to allow a later response to the current treatment regimen, or

- switch to a 2nd- or 3rd-line option, which may address the patient's symptoms and therapy preferences better

- refer the patient to a dermatologist or a centre that specialises in psoriasis.

If topical management is not enough to control psoriasis in a satisfactory manner for the patient and within a reasonable time frame, UV or systemic therapy should be administered according to the current Swiss S1 guidelines on the systemic treatment of psoriasis [7].
Classical Plaque Psoriasis

An overview of the recommended pathway is given in Figure 1.

\section{Induction Therapy}

For topical induction therapy of psoriasis, a once daily application of the fixed combination of calcipotriol 50 $\mu \mathrm{g} / \mathrm{g}(\mathrm{Cal})$ and betamethasone-dipropionate $0.5 \mathrm{mg} / \mathrm{g}$ (BD) for 2-8 weeks is most frequently used. For the choice of formulation, the patient's preference should be considered [13].

Once the treatment goal of clear/almost-clear skin is achieved, patients can be advised to reduce the frequency of application in a step-wise manner (e.g., to every other day for another 2 weeks) and to continue with a maintenance schedule of, for example, a twice weekly application. 
Table 2. Topical corticosteroid (TCS) classes and examples of active substances

\begin{tabular}{|c|c|}
\hline & Active substance/trade name \\
\hline Class I (mild) & Prednisolone $\left(\right.$ Promandol $\left.^{\circledR}\right)$; hydrocortisone acetate $\left(\right.$ Sanadermil ${ }^{\circledR}$, Dermacalm ${ }^{\circledR}$ ) \\
\hline Class II (moderate) & Clobetasone butyrate $\left(\right.$ Emovate $\left.^{\circledR}\right)$; hydrocortisone butyrate $0.1 \%$ (Locoid $^{\circledR}$ ) \\
\hline Class III (potent) & 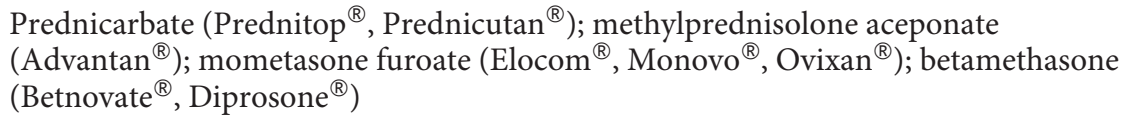 \\
\hline Class IV (very potent) & Clobetasol propionate (Dermovate ${ }^{\circledR}$, Clarelux ${ }^{\circledR}$, Clobex $^{\circledR}$ ) \\
\hline
\end{tabular}

\section{Cal/BD Fixed-Dose Combinations}

The benefit of combining Cal and BD is based on the superior efficacy (additive beneficial effect in reducing the hyperproliferation of keratinocytes and inflammation) and their synergistic effect on tolerability (lowering the risk of skin atrophy and reducing burning sensations, respectively), compared to the use of Cal or BD alone [16].

$\mathrm{Cal} / \mathrm{BD}$ fixed-dose combinations are available in 3 different formulations: ointment (Daivobet ${ }^{\circledR}$ Salbe/pommade), gel (Daivobet ${ }^{\circledR} \mathrm{Gel} /$ gel; Xamiol ${ }^{\circledR} \mathrm{Gel} /$ gel), and aerosol foam (Enstilar ${ }^{\circledR}$ Schaum/mousse). While the concentration of $\mathrm{Cal} / \mathrm{BD}$ is the same in all 3 formulations, the aerosol foam allows a state of supersaturation of the fully dissolved active compounds in the aerosol foam carrier [17, 18], which leads to an increased skin penetration and increased local bioavailability in the skin [19]. In clinical studies, the Cal/BD aerosol foam demonstrated a significantly higher (up to 55\% with treatment success after 4 weeks) and faster efficacy (median time to treatment success of 6 weeks) than the single compounds and the ointment and gel formulations [20-24]. Moreover, rapid relief from itching was observed $[25,26]$. The aerosol foam formulation is perceived by patients as being easy to apply, although not all body areas can be reached without help (e.g., the back).

Alternatively, as a 2nd-line treatment, monotherapy with topical corticosteroids (TCS) classes III/IV or topical vitamin $\mathrm{D}_{3}$ analogues can be considered $[27,28]$. In certain treatment situations, TCS can also be considered for the 1st-line treatment (Table 1). According to expert consensus and summary of product characteristics, a continuous, once/twice daily application of class IV TCS in monotherapy should not exceed 4 weeks.

\section{Topical Corticosteroids}

TCS have been approved for the treatment of psoriasis vulgaris since 1956 and are among the standard treatments for mild psoriasis. They can be used in combination with vitamin $\mathrm{D}_{3}$ analogues or as a monotherapy for the initial treatment of mild psoriasis. Their immunosuppressive and cell proliferation-inhibiting effect is due to specific receptors in the target cells of the skin. Their potency is graded into 4 classes (Table 2). TCS are often available as different formulations (ointments, creams, solutions, lotions, foams, and shampoos), so an individual, patient-preferred application can be selected. In general, most TCS are used once daily. Once the treatment goal has been achieved, they should be tapered down slowly. For reasons of practicability, they are usually applied in the evening [8].

BD applied twice daily showed a significant improvement or complete clearance in $47-56 \%$ of patients, and this was achieved with clobetasol propionate in $68-89 \%$ of patients [29]. Both are thus in the range of efficacy for systemic therapy [30].

Adverse drug reactions depend on the drug class of the preparation as well as the location and duration of its application. In decreasing order of frequency, burning, itching, folliculitis, hypertrichosis, perioral dermatitis, and hypopigmentation may occur. Long-term use of class III/ IV TCS can also cause striae, telangiectasia, and skin atrophy. When applied more frequently and/or on extensive areas and/or under occlusion, a systemic effect of adrenal suppression can occur, which bears the risk of developing rebound or pustular psoriasis when not tapered down slowly (as seen with oral corticosteroids). No serious adverse drug reactions to TCS in induction treatment have been described.

\section{Vitamin $D_{3}$ Analogues}

The vitamin $\mathrm{D}_{3}$ analogues or derivatives tacalcitol $(\mathrm{Cu}-$ ratoderm ${ }^{\circledR}$ ) and calcitriol (Silkis ${ }^{\circledR}$ ) were first approved in 1992 for the treatment of mild-to-moderate psoriasis vul- 
garis. These act via specific receptors in the target cells of the skin. Their effect is selective and depends very much on the differentiation level of the keratinocytes. In the case of fast-growing, non-differentiated keratinocytes, vitamin $\mathrm{D}_{3}$ analogues inhibit further growth; with slow-growing keratinocytes, a proliferation-enhancing effect occurs [30]. Besides the effect on the keratinocytes, vitamin $\mathrm{D}_{3}$ analogues inhibit the development of peripheral blood mononuclear cells (PBMC, e.g., lymphocytes and monocytes) in the blood and the expression of cytokines (e.g., interleukin [IL]-1 $\alpha$, IL-1 $\beta$, IL-2, IL-6, IL-8, and IL-12) [30]. The main effect is the inhibition of the proliferation and stimulation of keratinocyte differentiation.

Depending on the preparation, vitamin $\mathrm{D}_{3}$ analogues are applied once or twice daily. When applied according to the current guidelines, the indication is a BSA of up to $10 \%$. Therefore, the restriction of the application of vitamin $\mathrm{D}_{3}$ analogues to a maximum of $15-35 \%$ of the total BSA according to expert information has no practical relevance. Adverse drug effects of vitamin $\mathrm{D}_{3}$ analogues may occur in the form of local irritation (pruritus, burning, and erythema). No clinically relevant disturbances of the calcium metabolism are to be expected if they are limited to the stated maximum amount [30]. Individual cases of hypercalcemia have only been observed in cases where maximum levels are exceeded for longer periods. Vitamin $\mathrm{D}_{3}$ analogues are therefore suitable for induction and maintenance therapy $[8,13,31-33]$.

\section{Maintenance Therapy}

After successful induction therapy, the initial regimen can be altered to a maintenance regimen which is a similar approach to the proactive management concept applied for atopic eczema.

For the maintenance phase, the same therapeutic agents used in the induction phase should be considered but less frequently applied (e.g., $2 \times /$ week).

Standardized and simplified treatment application models result in a better clinical outcome than on-demand therapies [13,34]. Best evidence for a successful and effective topical long-term management is available for the Cal/BD fixed combination. In a comparative trial of psoriasis vulgaris, the 2-compound-gel formulation showed tolerability and cost-effectiveness superior to that of a mono-formulation [13,35]. Recently, a phase 3 trial comparing the efficacy and safety of the Cal/BD fixeddose combination aerosol foam versus placebo showed that the proactive twice weekly management of psoriasis

Swiss Treatment Pathway for Topical

Treatment of Psoriasis resulted in a $43 \%(95 \%$ CI $0.47-0.57)$ reduction in the risk of experiencing a first relapse compared to subjects in the placebo (vehicle) group $(p<0.001)$ [36].

Regarding the long-term application of TCS in fixed combinations, the current data on psoriasis, in contrast to the atopic eczema data, suggests no major risk of the occurrence of skin atrophy. The experimental data suggests that a combination of vitamin $\mathrm{D}_{3}$ and TCS has a mitigating effect on the risk of atrophy [37]. However, long-term studies with validated and objective measurement parameters for skin atrophy (e.g., sonography) and surveys of atrophy biomarkers are lacking. Long-term therapy with TCS as a monotherapy is considered obsolete and should not be performed. Besides the fixed-combination Cal/BD formulation, other treatment regimens including TCS class II/III and other vitamin $\mathrm{D}_{3}$ analogues can be considered as 2nd- or 3rd-line options for maintenance therapy. They can be applied daily or on certain weekdays.

\section{Special Situations and Specific Symptoms}

An overview of topical management regarding specific locations, symptoms, and individual circumstances is given in Table 1.

\section{Scalp Psoriasis}

In up to $79 \%$ of patients with psoriasis vulgaris, there is some degree of scalp involvement [38-40]. Lesions are characterised by demarcated plaques, either single, multiple, or confluent, with dry and silvery scales, and they commonly extend over the hairline of the upper forehead, temples, and retroauricular region (Fig. 2). The proportion of scalp involvement and severity varies greatly. Four of five patients with scalp psoriasis report a negative impact on their QoL. In addition, scalp psoriasis is often a particularly challenging element to treat, as it includes scaling and cosmetic embarrassment (due to the visibility of the lesions), itch, limited access with topical treatment to the (hairy) scalp, and the proximity of the sensitive facial skin [41]. Finally, sufficient soaking time (typically overnight) of topical treatment is often limited and efficacy is diminished due to the required rinsing off thereafter [40]. No other body area in psoriasis treatment depends so much on the personal preference of the individual patient due to site-specific, cosmetic, product comfort, and convenience reasons. Patients usually have a long history and experience with various treatment formulations and should be involved in the selection of the active ingredient and formulation. 


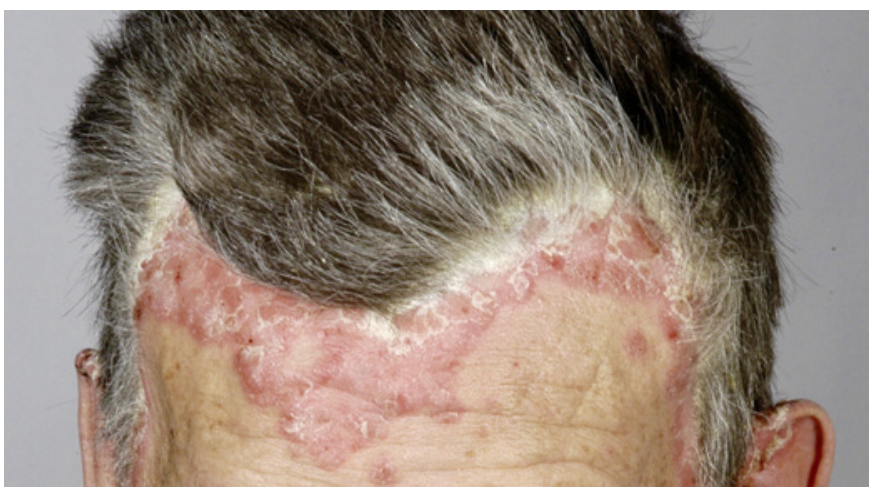

Fig. 2. Scalp psoriasis (image used with the courtesy of C.S.).

A Cochrane Review in 2016 revealed that Cal/BD fixed-dose combinations and TCS monotherapy were more effective and safer than vitamin $\mathrm{D}_{3}$ monotherapy for treating scalp psoriasis [40]. TCS foam [42] or shampoo [43] as well as the Cal/BD gel $[44,45]$ were specifically developed as an effective treatment for scalp psoriasis. More recently, the $\mathrm{Cal} / \mathrm{BD}$ aerosol foam formulation has also proven its efficacy in treating scalp psoriasis $[22$, $23,46]$.

The most important issues associated with adherence include a patient's acceptance of the formulation and perception of its effectiveness. In general, alcoholic solutions are inferior, due to the discomfort of burning sensations or additional drying of the scalp. The Cal/BD gel and aerosol foam formulations are well tolerated as they are completely water- and alcohol-free. However, the correct application and rinse-off procedure must be thoroughly addressed with the patient before treatment initiation. The Cal/BD aerosol foam formulation is well accepted by patients for effective induction therapy in the first 2-4 weeks of treatment. For maintenance, application frequency may be reduced to twice weekly, and a switch to $\mathrm{Cal} / \mathrm{BD}$ gel can be considered depending on the patient's preference.

\section{Inflammatory/Eczematous Forms}

The distinction between psoriasis and eczema can be difficult, leading some clinicians to use the term eczematous or inflammatory psoriasis. Eczema is used to describe a range of skin diseases that present with erythema, skin oedema, and dryness, in combination with pruritus. Inflammatory or eczematous psoriasis has a clinically heterogenic picture but retains the chronicity of classical psoriasis and mainly manifests with sharply demarcated, erythematous plaques, with the disease ac-

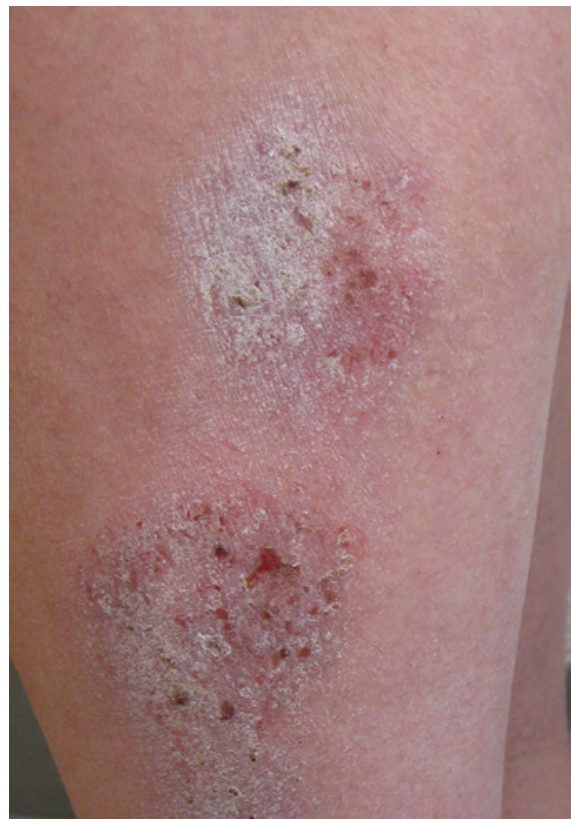

Fig. 3. Hyperinflammatory/eczematous psoriasis (image used with the courtesy of N.Y.).

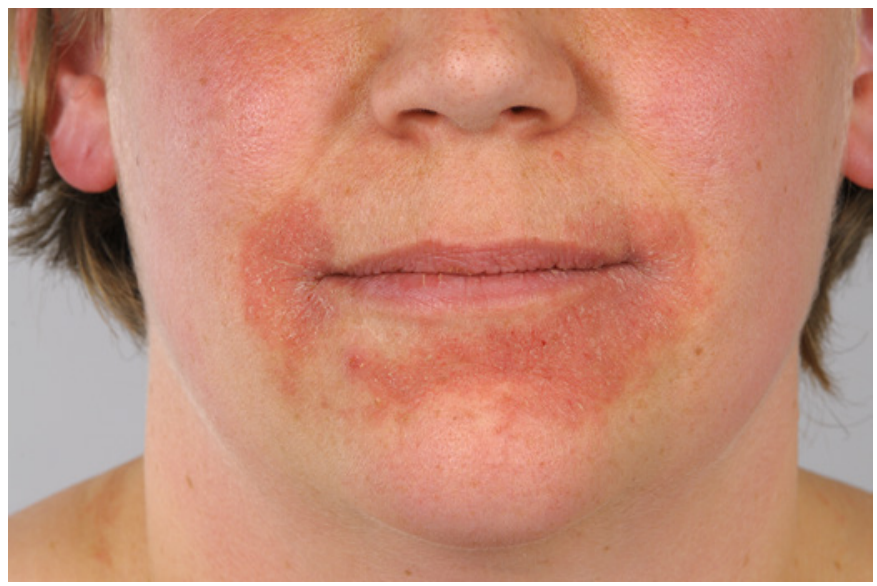

Fig. 4. Perioral facial psoriasis (image used with the courtesy of C.S.).

tivity sign at the borders and very slight/no scaling (Fig. 3). The definition of this entity primarily rests on the patient's history, clinical presentation, and response to treatment. In cases that are difficult to diagnose, we recommend confirming the diagnosis using skin biopsy. In patients with local forms of inflammatory or eczematous psoriasis lesions, it is advisable to start topical treatment with class III (potent) TCS. If this is not sufficient (after 1 week), it may be necessary to apply a class IV 
Fig. 5. Hyperkeratotic forms at the body trunk (a) or knee (b) (images used with the courtesy of N.Y.).
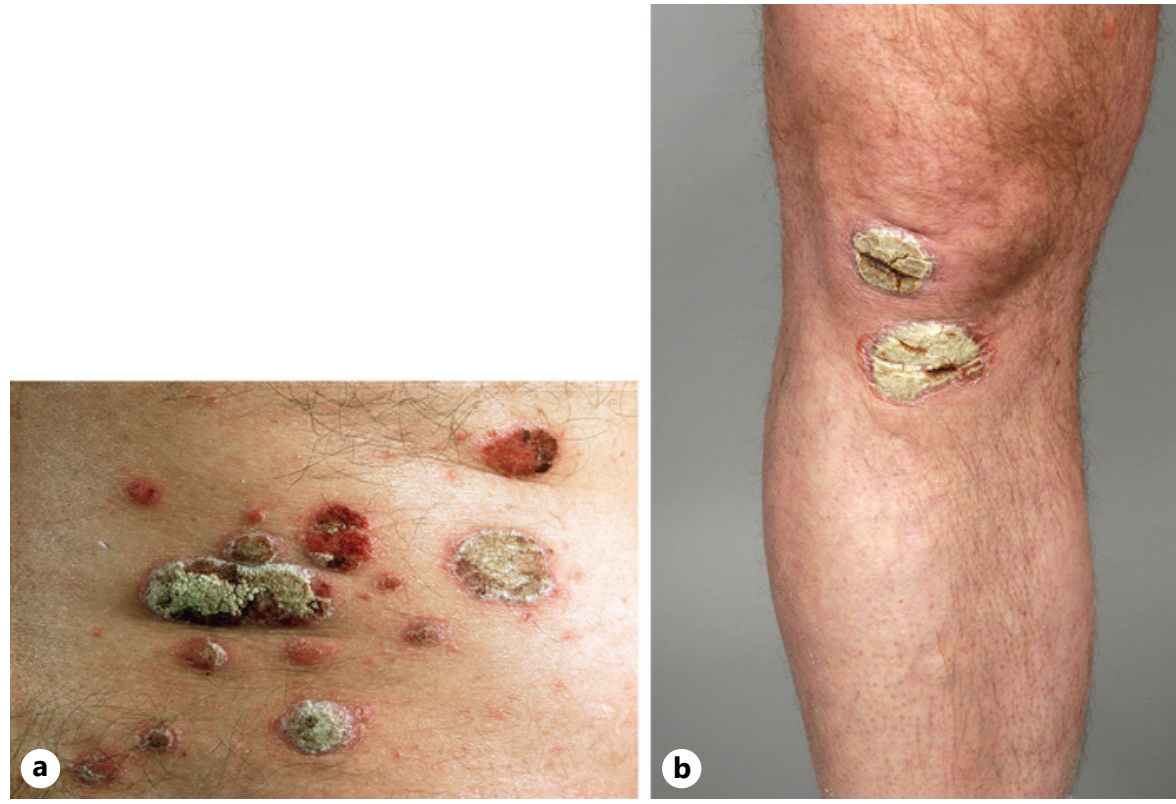

(very potent) TCS for 1 to (a maximum of) 4 weeks. Initially, a twice daily application can be carried out and this should be reduced to once daily after a week. It should be noted that $\mathrm{Cal}$ or the Cal/BD fixed combination can cause burning sensations if applied on eczematous forms. Once the first treatment success has been achieved, a switch to maintenance therapy with $\mathrm{Cal} / \mathrm{BD}$ fixed combination is recommended, analogous to the treatment pathway for psoriasis vulgaris.

\section{Facial Psoriasis}

Lesions on the facial skin (Fig. 4) can initially be treated with TCS class II/III once daily for 5-7 days. After a response within 2-4 weeks, the TCS should be tapered down. Application of TCS (class III) once weekly on the face is generally considered safe. Alternatively, TCS can be switched to topical calcineurin inhibitors (TCI; offlabel use) to avoid potential steroid side effects like skin atrophy. For maintenance, proactive therapy as for atopic eczema should be considered. Topical vitamin $\mathrm{D}_{3}$ analogues can also be considered.

TCI like tacrolimus ointment and pimecrolimus cream impact the activation of $\mathrm{T}$ cells, keratinocytes, and mast cells. Neither of these preparations has been approved for treatment of psoriasis, but several small-scale studies have shown efficacy, mainly under occlusion [47]. Small studies on TCI applied to facial and genito-anal skin have demonstrated efficacy regarding the outcome in these sensitive areas [48].

Swiss Treatment Pathway for Topical

Treatment of Psoriasis

\section{Intertriginous/Genital Psoriasis}

Intertriginous psoriasis, also referred to as inverse psoriasis, often requires a combination of treatments due to the inherent sensitivity, thinness, and occlusion of flexural skin. Unfortunately, most treatment recommendations lack the backing of high-quality evidence. Initiation of therapy is usually with class III TCS for up to 5 days. When triggering of inflammation by local dysbiosis or microbial colonization is suspected, combination products of TCS with topical antimicrobials can be used in the initial phase. Application of TCS ( \pm antimicrobials) should be quickly tapered down to once weekly for the maintenance therapy. TCI should be introduced if the disease is not yet sufficiently controlled (off-label). In contrast to their limited activity on regular psoriasis plaques [49], TCI have been shown to be efficacious in intertriginous and genital psoriasis [50]. Gribetz et al. [51] found a significant and rapid improvement in patient- and investigator-based assessments of 57 patients treated with pimecrolimus $1 \%$ applied twice daily for 8 weeks. Other studies with higher case numbers also describe a good efficacy of tacrolimus $0.1 \%$ [52-55].

\section{Hyperkeratotic Forms}

Hyperkeratosis may prevent the efficacy of a regular topical therapy due to the thickness of the upper stratum corneum (Fig. 5). In highly hyperkeratotic plaques, initial short-term ( $\leq 1$ week) keratolytic treatment with salicylic acid $(5-10 \%)$ or urea $(10-30 \%)$ containing topicals is 
Table 3. Summary of product characteristics, for during pregnancy and when breastfeeding, of selected topical treatment options in Switzerland [66]

\begin{tabular}{|c|c|c|c|}
\hline Drug & $\begin{array}{l}\text { Active ingredient } \\
\text { (brand name) }\end{array}$ & During pregnancy & When breastfeeding \\
\hline \multirow{6}{*}{ Class I } & All & Systemic effects if applied in a high potency, on large areas, and in the long term. & Do not use directly on the breasts. \\
\hline & Prednisolone (Promandol ${ }^{\circledR}$ ) & Do not use on large areas, in large amounts, or in the long term. & Can be excreted into the breast milk. \\
\hline & $\begin{array}{l}\text { Clobetasone butyrate } \\
\left(\text { Emovate }^{\circledR}\right)\end{array}$ & $\begin{array}{l}\text { Carefully assess the benefit/risk ratio. Use as short and limited as possible. In } \\
\text { animal models, abnormal fetal development has been observed. }\end{array}$ & $\begin{array}{l}\text { Not known if absorbed enough to be } \\
\text { excreted into the breast milk. }\end{array}$ \\
\hline & $\begin{array}{l}\text { Prednicarbate } \\
\left(\text { Prednitop }^{\circledR}, \text { Prednicutan }^{\circledR}\right)\end{array}$ & $\begin{array}{l}\text { 1st trimester: contraindicated if applied on }>\mathbf{3 0} \% \text { BSA; if absolutely necessary, } \\
\text { application on small areas is possible. } \\
\text { 2nd and 3rd trimesters: only very limited use. In animal models, s.c. } \\
\text { administration of high and systemically effective doses led to teratogenic effects. In } \\
\text { epidemiologic studies, systemic TCS did not reveal any embryotoxic effects, but } \\
\text { fetal growth retardation was observed with long-term use. This data is not relevant } \\
\text { if prednicarbate is used topically and at the recommended dose. }\end{array}$ & $\begin{array}{l}\text { Very limited use only, as insufficient } \\
\text { clinical data available. }\end{array}$ \\
\hline & $\begin{array}{l}\text { Methylprednisolone } \\
\text { aceponate }\left(\text { Advantan }^{\circledR}\right)\end{array}$ & $\begin{array}{l}\text { Do not use in the 1st trimester; epidemiologic human studies suggest an } \\
\text { increased risk of cleft lip and cleft palate if used during the 1st trimester. } \\
\text { In the } 2 \text { nd and 3rd trimesters, do not use on large areas, in the long term, } \\
\text { or under occlusion. In animal models, abnormal fetal development has } \\
\text { been observed. }\end{array}$ & $\begin{array}{l}\text { Not known if absorbed enough to be } \\
\text { excreted into the breast milk. }\end{array}$ \\
\hline & $\begin{array}{l}\text { Mometasone furoate } \\
\left(\text { Elocom }^{\circledR} \text {, Ovixan }{ }^{\circledR}\right) \\
\text { Betamethasone } \\
\left(\text { Betnovate }^{\circledR}\right)\end{array}$ & $\begin{array}{l}\text { Do not use if not really needed. In animal studies, reproduction toxicity } \\
\text { has been observed. }\end{array}$ & $\begin{array}{l}\text { Systemically absorbed amount is }<1 \% \text {, } \\
\text { so small amounts can be excreted into } \\
\text { the breast milk. If applied on breasts, } \\
\text { stop breastfeeding. }\end{array}$ \\
\hline Class IV & $\begin{array}{l}\text { Clobetasol } \\
\left(\text { Dermovate }^{\circledR}, \text { Clarelux }^{\circledR},\right. \\
\left.\text { Clobex }^{\circledR}\right)\end{array}$ & $\begin{array}{l}\text { Carefully assess benefit/risk ratio during pregnancy and breastfeeding. Use as } \\
\text { short and limited as possible. In animal models, abnormal fetal development has } \\
\text { been observed. }\end{array}$ & $\begin{array}{l}\text { Not known if absorbed enough to be } \\
\text { detected in the breast milk. }\end{array}$ \\
\hline \multirow[t]{2}{*}{ TCI* } & $\begin{array}{l}\text { Pimecrolimus } \\
\left(\text { Elidel }^{\circledR}\right)\end{array}$ & $\begin{array}{l}\text { Not yet investigated in humans, so should not be applied. When topically applied } \\
\text { in animal studies, no direct or indirect harming effects on pregnancy, fetal } \\
\text { development, birth, and postnatal development were observed. When systemically } \\
\text { applied, there was a toxic effect on fetal bone development. }\end{array}$ & $\begin{array}{l}\text { Not known whether excreted into the } \\
\text { breast milk. Use with caution. Do not } \\
\text { use on the breasts. }\end{array}$ \\
\hline & $\begin{array}{l}\text { Tacrolimus } \\
\left(\text { Protopic }^{\circledR}\right)\end{array}$ & $\begin{array}{l}\text { Insufficient data in humans. In animal studies, only toxic for reproductive } \\
\text { functions when applied systemically. Do not use if not really needed. }\end{array}$ & $\begin{array}{l}\text { After systemic administration, it is } \\
\text { excreted into the breast milk. Not } \\
\text { recommended. }\end{array}$ \\
\hline \multirow[t]{2}{*}{$\begin{array}{l}\text { Vitamin D3 } \\
\text { analogues }\end{array}$} & $\begin{array}{l}\text { Calcitriol } \\
\left(\text { Silkis }^{\circledR}\right)\end{array}$ & $\begin{array}{l}\text { Insufficient data for humans. In animal studies, teratogenicity and fetotoxic effects } \\
\text { have been observed when applied at very high dosages. Do not use except when a } \\
\text { strong indication. If used, then as limited as possible and control calcium levels. }\end{array}$ & $\begin{array}{l}\text { Oral calcitriol is excreted via the breast } \\
\text { milk. Absorption of topical calcitriol is } \\
\text { limited, but its use is not } \\
\text { recommended. }\end{array}$ \\
\hline & $\begin{array}{l}\text { Tacalcitol } \\
\left(\text { Curatoderm }{ }^{\circledR}\right)\end{array}$ & $\begin{array}{l}\text { No available controlled study data in women. In animal models, no toxic effects on } \\
\text { reproduction were observed. Do not use if not clearly necessary. }\end{array}$ & $\begin{array}{l}\text { Do not use. Not known whether } \\
\text { excreted into the breast milk. }\end{array}$ \\
\hline $\begin{array}{l}\mathrm{Cal} / \mathrm{BD} \\
\text { fixed } \\
\text { combination }\end{array}$ & $\begin{array}{l}\text { Cal/BD } \\
\left(\text { Daivobet }^{\circledR}, \text { Enstilar }^{\circledR},\right. \\
\left.\text { Xamiol }^{\circledR}\right)\end{array}$ & $\begin{array}{l}\text { Insufficient data. In animal studies, oral Cal did not show teratogenic effects, but } \\
\text { there was reproduction toxicity. Glucocorticoids did show reproduction toxicity. } \\
\text { In epidemiological studies (<300 pregnancies), no congenital abnormalities were } \\
\text { observed. Do not use if not clearly necessary. }\end{array}$ & $\begin{array}{l}\text { BD is excreted into milk, but there is } \\
\text { no available data on Cal. Use with } \\
\text { caution. If applied to the breasts, } \\
\text { stop breastfeeding. }\end{array}$ \\
\hline $\begin{array}{l}\text { Salicylic } \\
\text { acid }\end{array}$ & $\begin{array}{l}\text { Salicylic acid } \\
\text { (Diprosalic }^{\circledR} \text { Excipial } \\
\text { Kerasal }^{\circledR} \text {, and others) }\end{array}$ & $\begin{array}{l}\text { No data available. In animal studies, reproduction toxicity has been observed. } \\
\text { Do not use during pregnancy if not clearly necessary. }\end{array}$ & Do not use. \\
\hline Tar & $\begin{array}{l}\text { Ammonium } \\
\text { bituminosulphonate } \\
\left(\text { Ichtholan }{ }^{\circledR}\right)\end{array}$ & $\begin{array}{l}\text { No human data available. From animal data, reproduction toxicity observed. } \\
\text { No risk to the embryo or fetus observed during long-lasting clinical experience. } \\
\text { If used on small areas, only limited resorption assumed. Do not use on large areas } \\
\text { Only use if clearly necessary. }\end{array}$ & $\begin{array}{l}\text { No data available on whether it is } \\
\text { excreted into the breast milk. Only use } \\
\text { if clearly necessary. Do not use in the } \\
\text { area of the breasts. }\end{array}$ \\
\hline
\end{tabular}

* Off-label for psoriasis. BSA, body surface area; Cal, calcipotriol; BD, betamethasone; TCS, topical corticosteroids; TCI, topical calcineurin inhibitors. 
recommended. This is followed with a class III/IV TCS applied once or twice daily with or without occlusion, or a Cal/BD fixed-dose combination with a gradual reduction in frequency as illustrated in the Treatment Pathway section [56]. When larger areas than palms or soles are affected, or when applied extensively on thin skin, salicylic acid absorbed through the skin can have hepatotoxic, nephrotoxic, and neurotoxic side effects. Alternatively, there are reports demonstrating that the foam formulation of Cal/BD fixed-dose combination, applied directly without pre-treatment with salicylic acid or urea containing topicals on hyperkeratotic lesions, can be very effective as well [57].

\section{Palmoplantar Psoriasis}

Palmoplantar psoriasis features hyperkeratotic, pustular, or mixed morphologies and is associated with a substantial impairment in QoL. The cause of palmoplantar psoriasis is a combination of genetic and environmental factors. Environmental triggers include smoking, irritants, friction, and manual or repetitive trauma [58]. Most of the patients with palmoplantar pustulosis are female and current or former smokers. Paradoxically, this is also known to be a side effect of anti-TNF- $\alpha$ therapy in psoriasis. Whereas topical treatment for pustulosis-type palmoplantar psoriasis is usually disappointing, it is an option for plaque-type palmoplantar psoriasis. This usually requires a keratolytic treatment due to the hyperkeratosis, as defined above, followed by a potent-to-very potent class III/IV TCS. An initial occlusive therapy accelerates the onset of action. After approximately 2-4 weeks of therapy, a fixed combination of $\mathrm{Cal} / \mathrm{BD}$ can be considered for maintenance therapy.

\section{Pregnancy and Breastfeeding}

The topical management of psoriasis during pregnancy and lactation is challenging as many topical treatments are contraindicated $[59,60]$ (Table 3 ).

Multiple large-scale, population-based studies and a Cochrane review on pregnant women using TCS did not show any increased rate of malformations or preterm delivery [61], but there might be a risk of fetal growth restriction with high-potency TCS [62]. The use of $>300 \mathrm{~g}$ of potent TCS during the entire pregnancy is associated with low birth weights [62]. Special attention should be paid to areas at risk for striae formation, e.g., the breasts, thighs, and abdomen [63].

There are no studies on the use of TCI during pregnancy. Data on systemic use does not show any increased risk of congenital malformations, but there is an increased risk of prematurity and low birth weight. Additionally, systemic absorption of topical tacrolimus is very low [64]. Therefore, TCI may be preferred in corticosteroid-refractory cases in areas at risk for striae formation as well as the face and intertriginous areas.

Anthralin (dithranol, or cignolin in Germany), tazarotene, and coal tar are not recommended due to their suspected or known mutagenic or teratogenic properties, and calcipotriene and salicylic acid are not recommended due to insufficient data $[62,65]$.

In breastfeeding women, TCS should be applied directly after nursing and carefully removed before the next feed [63-65].

Recommendation for pregnancy: 1st-line recommendations are moisturisers and low-to-mild potency TCS of short duration.

\section{Conclusion}

Topical therapy is crucial for the successful management of psoriasis. The aim of this Swiss expert consensus was to optimise the use and outcome of topical treatment for the short- and long-term management of psoriasis as well as in treatment situations specific to Switzerland.

In clinical practice, $\mathrm{Cal} / \mathrm{BD}$ fixed-dose combinations in various formulations are most frequently used for induction and maintenance therapy. Monovalent treatments with topical corticosteroids are also suitable for the induction phase in certain circumstances. Simplified, standardised, shared individual decision models, that take into consideration patients' preferences and previous treatment experience, result in better treatment outcomes than treatment-on-demand models. Defining treatment goals and realistic expectations at the onset of treatment also help to ensure adherence.

\section{Key Message}

We have presented practical recommendations and an expert opinion on the topical management of mild-to-moderate psoriasis.

\section{Statement of Ethics}

Informed patient consent was obtained for the use of all photographs. 


\section{Conflict of Interest Statement}

J.-T.M. is an employee of USZ and holds a "Filling the GAP" scholarship. She has served as advisor and/or received speaking fees and/or participated in clinical trials sponsored by AbbVie, Almirall, Amgen, BMS, Celgene, Eli Lilly, LEO Pharma, JanssenCilag, MSD, Novartis, Pfizer, Pierre Fabre, Roche, Sanofi, and UCB. F.A. has served as an investigator, speaker, and/or advisor for Abbvie, Celgene, Leo Pharma, Galderma, Eli Lilly, JanssenCilag, Novartis, Galderma, and Almirall, but has no financial interest nor holds any shares of any pharmaceutical company. C.C. has served as a scientific adviser and/or clinical study investigator and/or paid speaker for AbbVie, Actelion, Amgen, BMS, Celgene, Galderma, Incyte, Janssen, LEO Pharma, Lilly, MSD, Novartis, Pfizer, and UCB. A.C. has been a consultant and advisor and/or received speaking fees and/or grants and/or served as an investigator in clinical trials for the following companies: AbbVie, Almirall, Amgen, BMS, Celgene, Eli Lilly, Janssen-Cilag, LEO Pharma, Novartis, Pfizer and Sanofi. A. Cozzio does not hold any shares or other financial interest in any related pharmaceutical company. P.H. has served as a speaker, and/or advisor for AbbVie, Almirall, Amgen, Celgene, Eli Lilly, Galderma, Janssen, LEO Pharma, Novartis, and Sanofi. A.J. has been a consultant and advisor and/or received speaking fees and/or grants and/ or served as an investigator in clinical trials for the following companies: AbbVie, Almirall, Amgen, BMS, Boehringer Ingelheim, Celgene, Eli Lilly, GSK, LEO Pharma, Janssen-Cilag, MSD, Novartis, and Sanofi. A.G.A.K has served as an investigator, speaker, and/or advisor for AbbVie, Abbott, Janssen, Eli Lilly, MSD, Pfizer, Celgene, Novartis, Actelion, LEO Pharma, Amgen, and Alk-Abello but does not hold any shares or other financial interest in any related pharmaceutical company. E.L. has served as an investigator, speaker, and/or advisor from Abbvie, Amgen, Celgene, Eli Lilly, Galderma, Janssen, Leo Pharma, Novartis, MSD, Sanofi, and Pfizer. A.-K.L. has served as an investigator, speaker, and/or advisor for AbbVie, Celgene, Eli Lilly, LEO Pharma, Novartis, Pfizer, and Sanofi. C.M. has received honoraria for Advisory Boards from LEO Pharma, AbbVie, Almirall, Celgene, and Eli Lilly. C.S. has received honoraria as adviser for Abbvie, LEO Pharma, Lilly, and Novartis and has received research fund- ing from PPM Services. R.T. has served as speaker for LEO Pharma. N.Y. has served as an investigator, speaker and/or advisor for AbbVie, Almirall, Amgen, Celgene, Eli Lilly, Galderma, Janssen, LEO Pharma, MSD, Novartis, Pfizer, Sanofi, and UCB. M.D. has served as speaker and/or consultant for Astellas, Beiersdorf, BMS, Celgene, Galderma, GSK, LEO Pharma, Sobi, Uniqure, and Vertex. A.A.N. has been a consultant and advisor and/or received speaking fees and/or grants and/or served as an investigator in clinical trials for the following companies: AbbVie, Almirall, Amgen, BMS, Boehringer Ingelheim, Celgene, Eli Lilly, GSK, LEO Pharma, Janssen-Cilag, MSD, Novartis, Pfizer, Sandoz, Sanofi, and UCB; he does not hold any shares or other financial interest in any related pharmaceutical company.

\section{Funding Sources}

Medical writing and publication of the manuscript were funded by a grant from LEO Pharma, Switzerland.

\section{Author Contributions}

All authors contributed to the conception of the work and interpretation of the data on the practical implications for the topical management of psoriasis. After each author completed a survey on topical management of different types of psoriasis, practical recommendations were developed and consensus reached by the group in several meetings and telephone conferences. Scientific rationale and background were drafted and clinical photographs contributed by the following authors: treatment pathway and general recommendations for classical plaque-type psoriasis by J.T.M., M.D., and A.A.N.; scalp psoriasis by R.T., eczematous psoriasis by A.J., N.Y., P.H., and F.A.; facial and genital psoriasis by C.S. and N.Y.; hyperkeratotic forms by C.C. and A.J.; palmoplantar forms by A.C. and E.L., pregnancy and breastfeeding data by A.G.A.K., A.-K.L. and C.M.; collation of all parts and alignment of reviewer comments were done by J.-T.M and M.D. The final version was critically reviewed and approved by all authors.

\section{References}

1 Globaler Bericht zur Schuppenflechte der WHO (2016). Available from: https://www. psonet.de/wp-content/uploads/GlobalerBericht-Schuppenflechte-2016, WHO report 2016.pdf (June 2020).

2 Boehncke WH, Schön MP. Psoriasis. Lancet. 2015 Sep;386(9997):983-94.

3 Bagel J. Treat to Target in Psoriasis: A RealWorld Experience With Biologics and Adjunctive Topical Therapy. J Drugs Dermatol. 2018 Aug; 17(8):918.

4 Mrowietz U, Kragballe K, Reich K, Spuls P, Griffiths CE, Nast A, et al. Definition of treatment goals for moderate to severe psoriasis: a European consensus. Arch Dermatol Res. 2011 Jan;303(1):1-10.
5 Ros S, Puig L, Carrascosa JM. Cumulative life course impairment: the imprint of psoriasis on the patient's life. Actas Dermosifiliogr. 2014 Mar;105(2):128-34.

6 Blome C, Gosau R, Radtke MA, Reich K, Rustenbach SJ, Spehr C, et al. Patient-relevant treatment goals in psoriasis. Arch Dermatol Res. 2016 Mar;308(2):69-78.

7 Kolios AG, Yawalkar N, Anliker M, Boehncke WH, Borradori L, Conrad C, et al. Swiss S1 Guidelines on the Systemic Treatment of Psoriasis Vulgaris. Dermatology. 2016;232(4): 385-406.
8 Körber A, Wilsmann-Theis D, Augustin M, von Kiedrowski R, Mrowietz U, Rosenbach T, et al.; PsoNet Förderverein. Topische Therapie bei Psoriasis vulgaris - ein Behandlungspfad. J Dtsch Dermatol Ges. 2019 May; 17(Suppl 4):3-14.

9 Mahil SK, Wilson N, Dand N, Reynolds NJ, Griffiths CE, Emsley R, et al.; BADBIR study group and the PSORT consortium. Psoriasis treat to target: defining outcomes in psoriasis using data from a real-world, populationbased cohort study (the British Association of Dermatologists Biologics and Immunomodulators Register, BADBIR). Br J Dermatol. 2020 May;182(5):1158-66. 
10 Hong CH, Papp KA, Lophaven KW, Skallerup P, Philipp S. Patients with psoriasis have different preferences for topical therapy, highlighting the importance of individualized treatment approaches: randomized phase IIIb PSO-INSIGHTFUL study. J Eur Acad Dermatol Venereol. 2017 Nov;31(11): 1876-83.

11 Svendsen MT, Feldman SR, Tiedemann SN, Sørensen AS, Rivas CM, Andersen KE. Psoriasis patient preferences for topical drugs: a systematic review. J Dermatolog Treat. 2019 Oct;1-6.

12 Reich K, Zschocke I, Bachelez H, de Jong EM, Gisondi P, Puig L, et al.; PSO-TOP study group. A Topical Treatment Optimization Programme (TTOP) improves clinical outcome for calcipotriol/betamethasone gel in psoriasis: results of a 64-week multinational randomized phase IV study in 1790 patients (PSO-TOP). Br J Dermatol. 2017 Jul;177(1): 197-205.

13 Augustin M, Mrowietz U, Bonnekoh B, Rosenbach T, Thaçi D, Reusch M, et al. Topical long-term therapy of psoriasis with vitamin D3 analogues, corticosteroids and their two compound formulations: position paper on evidence and use in daily practice. J Dtsch Dermatol Ges. 2014 Aug;12(8):667-82.

14 Luger T, Seite S, Humbert P, Krutmann J, Triller R, Dréno B. Recommendations for adjunctive basic skin care in patients with psoriasis. Eur J Dermatol. 2014 Mar-Apr;24(2): 194-200.

15 Thaçi D, Augustin M, Krutmann J, Luger T. Importance of basic therapy in psoriasis. J Dtsch Dermatol Ges. 2015 May;13(5):415-8.

16 Segaert S, Ropke M. The biological rationale for use of vitamin d analogs in combination with corticosteroids for the topical treatment of plaque psoriasis. J Drugs Dermatol. 2013 Aug;12(8):e129-37.

17 Puig L, Carretero G. Update on Topical Treatments for Psoriasis: The Role of Calcipotriol Plus Betamethasone Dipropionate Aerosol Foam. Actas Dermosifiliogr. 2019 Mar; 110(2):115-23.

18 Basse LH, Olesen M, Lacour JP, QueilleRoussel C. Enhanced in vitro skin penetration and antipsoriatic effect of fixed combination Calcipotriol plus betamethasone dipropionate in an innovative foam vehicle. J Invest Dermatol. 2014;134:33.

19 Lind M, Nielsen KT, Schefe LH, Nørremark $\mathrm{K}$, Eriksson AH, Norsgaard H, et al. Supersaturation of Calcipotriene and Betamethasone Dipropionate in a Novel Aerosol Foam Formulation for Topical Treatment of Psoriasis Provides Enhanced Bioavailability of the Active Ingredients. Dermatol Ther (Heidelb). 2016 Sep;6(3):413-25.

20 Koo J, Tyring S, Werschler WP, Bruce S, Olesen M, Villumsen J, et al. Superior efficacy of calcipotriene and betamethasone dipropionate aerosol foam versus ointment in patients with psoriasis vulgaris-A randomized phase II study. J Dermatolog Treat. 2016;27(2):120-7.
21 Leonardi C, Bagel J, Yamauchi P, Pariser D, Xu Z, Olesen M, et al. Efficacy and Safety of Calcipotriene Plus Betamethasone Dipropionate Aerosol Foam in Patients With Psoriasis Vulgaris-a Randomized Phase III Study (PSO-FAST). J Drugs Dermatol. 2015 Dec; 14(12):1468-77.

22 Paul C, Stein Gold L, Cambazard F, Kalb RE, Lowson D, Bang B, et al. Calcipotriol plus betamethasone dipropionate aerosol foam provides superior efficacy vs. gel in patients with psoriasis vulgaris: randomized, controlled PSO-ABLE study. J Eur Acad Dermatol Venereol. 2017 Jan;31(1):119-26.

23 Lebwohl M, Tyring S, Bukhalo M, AlonsoLlamazares J, Olesen $\mathrm{M}$, Lowson $\mathrm{D}$, et al. Fixed Combination Aerosol Foam Calcipotriene $0.005 \%$ (Cal) Plus Betamethasone Dipropionate $0.064 \%$ (BD) is More Efficacious than $\mathrm{Cal}$ or BD Aerosol Foam Alone for Psoriasis Vulgaris: A Randomized, Double-blind, Multicenter, Three-arm, Phase 2 Study. J Clin Aesthet Dermatol. 2016 Feb;9(2):34-41.

24 Menter A, Gold LS, Koo J, Villumsen J, Rosén M, Lebwohl M. Fixed-Combination Calcipotriene Plus Betamethasone Dipropionate Aerosol Foam Is Well Tolerated in Patients with Psoriasis Vulgaris: Pooled Data from Three Randomized Controlled Studies. Skinmed. 2017 Apr;15(2):119-24.

25 Jalili A, Lebwohl M, Stein Gold L, Andersen SB, Jensen KL, Pink AE, et al. Itch relief in patients with psoriasis: effectiveness of calcipotriol plus betamethasone dipropionate foam. J Eur Acad Dermatol Venereol. 2019 Apr;33(4):709-17.

26 Pink AE, Jalili A, Berg P, Calzavara-Pinton PG, de la Cueva Dobao P, Thaçi D, et al. Rapid onset of action of calcipotriol/betamethasone dipropionate cutaneous foam in psoriasis, even in patients with more severe disease. J Eur Acad Dermatol Venereol. 2019 Jun; 33(6):1116-23.

27 Samarasekera EJ, Sawyer L, Wonderling D, Tucker R, Smith CH. Topical therapies for the treatment of plaque psoriasis: systematic review and network meta-analyses. Br J Dermatol. 2013 May;168(5):954-67.

28 Mason A, Mason J, Cork M, Hancock H, Dooley G. Topical treatments for chronic plaque psoriasis: an abridged Cochrane systematic review. J Am Acad Dermatol. 2013 Nov;69(5):799-807.

29 Nast A, Boehncke WH, Mrowietz U, Ockenfels HM, Philipp S, Reich K, et al. [S3-guidelines for the treatment of psoriasis vulgaris Update 2011]. J Dtsch Dermatol Ges. 2011 Jun;9(Suppl 2):S1-104.

30 Wilsmann-Theis D, Gerdes S, Körber A, et al. Topische Therapie der Psoriasis, 1. Auflage Bremen: UNI-MED, 2016.

31 Gerritsen MJ, VanDe Kerkhof PC, Langner A. Long-term safety of topical calcitriol 3 microg g(-1) ointment. Br J Dermatol. 2001;144(Suppl 58): 1719

32 Langner A, Ashton P, Van De Kerkhof PC, Verjans H. A long-term multicentre assessment of the safety and tolerability of calcitriol ointment in the treatment of chronic plaque psoriasis. Br J Dermatol. 1996 Sep;135(3): 385-9.

33 Van de Kerkhof PC, Van Harten J, Verjans H. A long term assessment of the safety and tolerability of calcitriol ointment in the treatment of chronic plaque psoriasis. J Dermatolog Treat. 1996; 7(sup1):S11-4.

34 Piaserico S, Manfredini S, Borghi A, Gisondi P, Pazzaglia M, Stinco G, et al. How to improve adherence to treatment in patients with mild-to-moderate psoriasis. G Ital Dermatol Venereol. 2018 Oct;153(5):692-7.

35 Lambert J, Hol CW, Vink J. Real-life effectiveness of once-daily calcipotriol and betamethasone dipropionate gel vs. ointment formulations in psoriasis vulgaris: final analysis of the 52-week PRO-long study. J Eur Acad Dermatol Venereol. 2015 Dec;29(12):2349-55.

36 Lebwohl M, Lacour JP, Liljedahl M, Lynde C, Holst Mørch M, Snel-Prentø AM, et al. Longterm proactive management of psoriasis vulgaris with fixed-dose combination of calcipotriene $0.005 \%$ and betamethasone dipropionate $0.064 \%$ foam: results of a Phase III randomized controlled trial; AAD 2020, Chicago, Poster \# 18223.

37 Norsgaard H, Gonzalez T, Duenstl G, et al. Beneficial effects of the fixed combination of calcipotriol and betamethasone dipropionate on skin atrophy biomarkers. Poster presented at 21st EADV, 2012: No. PRA12-0845.

38 van de Kerkhof PC, Steegers-Theunissen RP, Kuipers MV. Evaluation of topical drug treatment in psoriasis. Dermatology. 1998;197(1): 31-6.

39 van de Kerkhof PC, de Hoop D, de Korte J, Kuipers MV. Scalp psoriasis, clinical presentations and therapeutic management. Dermatology. 1998;197(4):326-34.

40 Schlager JG, Rosumeck S, Werner RN, Jacobs A, Schmitt J, Schlager C, et al. Topical treatments for scalp psoriasis. Cochrane Database Syst Rev. 2016 Feb;2:CD009687.

41 Schlager JG, Rosumeck S, Werner RN, Jacobs A, Schmitt J, Schlager C, et al. Topical treatments for scalp psoriasis: summary of a Cochrane Systematic Review. Br J Dermatol. 2017 Mar;176(3):604-14.

42 Payne J, Habet KA, Pona A, Feldman SR. A Review of Topical Corticosteroid Foams. J Drugs Dermatol. 2019 Aug;18(8):756-70.

43 Reygagne P, Mrowietz U, Decroix J, de Waard-van der Spek FB, Acebes LO, Figueiredo A, et al. Clobetasol propionate shampoo $0.05 \%$ and calcipotriol solution $0.005 \%$ : a randomized comparison of efficacy and safety in subjects with scalp psoriasis. J Dermatolog Treat. 2005 Feb;16(1):31-6.

44 Jemec GB, Ganslandt C, Ortonne JP, Poulin $\mathrm{Y}$, Burden $\mathrm{AD}$, de Unamuno $\mathrm{P}$, et al. A new scalp formulation of calcipotriene plus betamethasone compared with its active ingredients and the vehicle in the treatment of scalp psoriasis: a randomized, double-blind, controlled trial. J Am Acad Dermatol. 2008 Sep; 59(3):455-63. 
45 van de Kerkhof PC, Hoffmann V, Anstey A, Barnes L, Bolduc C, Reich K, et al. A new scalp formulation of calcipotriol plus betamethasone dipropionate compared with each of its active ingredients in the same vehicle for the treatment of scalp psoriasis: a randomized, double-blind, controlled trial. Br J Dermatol. 2009 Jan;160(1):170-6.

46 Anderko M, Navarro Triviño FJ, Sharples CL. Calcipotriol Plus Betamethasone Dipropionate Aerosol Foam For Scalp Psoriasis. Clin Cosmet Investig Dermatol. 2019 Sep;12:699-705.

47 Remitz A, Reitamo S, Erkko P, Granlund H, Lauerma AI. Tacrolimus ointment improves psoriasis in a microplaque assay. Br J Dermatol. 1999 Jul;141(1):103-7.

48 Jacobi A, Braeutigam M, Mahler V, Schultz E, Hertl M. Pimecrolimus $1 \%$ cream in the treatment of facial psoriasis: a 16-week open-label study. Dermatology. 2008;216(2):133-6.

49 Zonneveld IM, Rubins A, Jablonska S, Dobozy A, Ruzicka T, Kind P, et al. Topical tacrolimus is not effective in chronic plaque psoriasis. A pilot study. Arch Dermatol. 1998 Sep; 134(9):1101-2.

50 Amichai B. Psoriasis of the glans penis in a child successfully treated with Elidel (pimecrolimus) cream. J Eur Acad Dermatol Venereol. 2004 Nov;18(6):742-3.

51 Gribetz C, Ling M, Lebwohl M, Pariser D, Draelos Z, Gottlieb AB, et al. Pimecrolimus cream $1 \%$ in the treatment of intertriginous psoriasis: a double-blind, randomized study. J Am Acad Dermatol. 2004 Nov;51(5):731-8.

52 Brune A, Miller DW, Lin P, Cotrim-Russi D, Paller AS. Tacrolimus ointment is effective for psoriasis on the face and intertriginous ar- eas in pediatric patients. Pediatr Dermatol. 2007 Jan-Feb;24(1):76-80.

53 Steele JA, Choi C, Kwong PC. Topical tacrolimus in the treatment of inverse psoriasis in children. J Am Acad Dermatol. 2005 Oct; 53(4):713-6.

54 Lebwohl M, Freeman A, Chapman MS, Feldman S, Hartle J, Henning A. Proven efficacy of tacrolimus for facial and intertriginous psoriasis. Arch Dermatol. 2005 Sep;141(9): 1154.

55 Lebwohl M, Freeman AK, Chapman MS, Feldman SR, Hartle JE, Henning A; Tacrolimus Ointment Study Group. Tacrolimus ointment is effective for facial and intertriginous psoriasis. J Am Acad Dermatol. 2004 Nov;51(5):723-30.

56 Miceli A, Schmieder GJ. Palmoplantar Psoriasis. June 3, 2019. StatPearls [Internet]. Treasure Island (FL): StatPearls Publishing; January 2020. Available from: http://www.ncbi. nlm.nih.gov/books/NBK448142/.

57 Pinter A, Thormann H, Angeletti F, Jalili A. Calcipotriol/betamethasone dipropionate aerosol foam for the treatment of psoriasis vulgaris: case series and review of the literature. Clin Cosmet Investig Dermatol. 2018 Oct;11:451-9.

58 Miceli A, Schmieder GJ. Palmoplantar Psoriasis. June 3, 2019. StatPearls [Internet]. Treasure Island (FL): StatPearls Publishing; January 2019. Available from: http://www.ncbi. nlm.nih.gov/books/NBK448142/.

59 Bae YS, Van Voorhees AS, Hsu S, Korman NJ, Lebwohl MG, Young M, et al.; National Psoriasis Foundation. Review of treatment options for psoriasis in pregnant or lactating women: from the Medical Board of the $\mathrm{Na}$ tional Psoriasis Foundation. J Am Acad Dermatol. 2012 Sep;67(3):459-77.

60 Hoffman MB, Farhangian M, Feldman SR Psoriasis during pregnancy: characteristics and important management recommendations. Expert Rev Clin Immunol. 2015 Jun 11(6):709-20.

61 Chi CC, Wang SH, Wojnarowska F, Kirtschig G, Davies E, Bennett C. Safety of topical corticosteroids in pregnancy. Cochrane Database Syst Rev. 2015 Oct;(10):CD007346

62 Chi CC, Wang SH, Mayon-White R, Wojnarowska F. Pregnancy outcomes after maternal exposure to topical corticosteroids: a UK population-based cohort study. JAMA Dermatol. 2013 Nov;149(11):1274-80.

63 Murase JE, Heller MM, Butler DC. Safety of dermatologic medications in pregnancy and lactation: part I. Pregnancy. J Am Acad Dermatol. 2014 Mar;70(3):401.e1-14.

64 Vestergaard C, Wollenberg A, Barbarot S, Christen-Zaech S, Deleuran M, Spuls P, et al. European task force on atopic dermatitis position paper: treatment of parental atopic dermatitis during preconception, pregnancy and lactation period. J Eur Acad Dermatol Venereol. 2019 Sep;33(9):1644-59.

65 Gottlieb AB, Ryan C, Murase JE. Clinical considerations for the management of psoriasis in women. Int J Womens Dermatol. 2019 Apr;5(3):141-50.

66 Swiss product information and/or Swiss compendium for therapeutic drugs accessed via Swiss product information. Available from: www.swissmedicinfo.ch or https://compendium.ch (June 4, 2020). 